MATEC Web of Conferences 47, 02013 (2016)

DOI: $10.1051 /$ matecconf/20164702013

(C) Owned by the authors, published by EDP Sciences, 2016

\title{
Amplitude Distribution of Emission Wave for Cracking Process
}

\author{
Shahiron Shahidan ${ }^{1, a}$, Sharifah Salwa Mohd Zuki ${ }^{1}$, Mustaqqim Abdul Rahim ${ }^{2}$, Noorwirdawati Ali ${ }^{1}$ and \\ Noridah Mohamad ${ }^{1}$ \\ ${ }^{1}$ Department of Structural and Material Engineering, Faculty of Civil and Environmental Engineering, Universiti Tun \\ Hussien Onn Malaysia,86400, Parit Raja, Johor, Malaysia \\ ${ }^{2}$ Civil Engineering Department, School of Environmental Engineering, Universiti Malaysia Perlis, 02600 Arau, Perlis, \\ Malaysia
}

\begin{abstract}
Acoustic emission technique is a method of assessment for structural health monitoring system. This technique is an effective tool for the evaluation of any system without destroying the material conditions. It enables early crack detections and has very high sensitivity to crack growth. The crack patterns in concrete beam have been identified according to the type of cracking process and the crack classifications using the AE data parameters are mainly based on the AE amplitude, rise time, and average frequency. These data parameters have been analysed using statistical methods of $b$-value analysis. This research paper will mainly focus on the utilization of statistical $b$-value analysis in evaluating the emission amplitude distribution of concrete beams. The beam specimens (150 X 250 X 1900) mm were prepared in the laboratory system and tested with the four point bending test using cyclic loading together with acoustic emission monitoring system. The results showed that this statistical analysis is promising in determining the cracking process in concrete beams.
\end{abstract}

\section{Introduction}

Structural concrete bridges are highly at risk in terms of structural conditions due to over loading compared to other structures. This condition occurs due to the increase of daily traffic loading on bridges. The most common defects found on superstructure concrete bridges are micro-cracking and macro-cracking [1-3]. These types of damage are becoming serious and have caused great concern among the public [4]. The AE technique evaluation method has been found to be more effective and accurate for developing damage grading systems. This system is very useful and significant for assessing concrete structures such as bridges for daily use and deterioration in buildings to classify the differences of class condition in concrete structures [3-5].

In the $\mathrm{AE}$ evaluation method, many researchers have developed a technique to identify the damage mechanism using AE signal parameters such as signal strength, hits, amplitude and wave energy [6-7]. These AE parameters have been used extensively in the evaluation system. One approach being used to evaluate the damage mechanism in concrete material is b-value analysis [8]. $b$-value analysis is a distribution of the frequency of AE hits with amplitude as well as with cumulative frequency. This method of analysis has been widely utilized in seismology to characterize the earthquake population

\footnotetext{
${ }^{a}$ Corresponding author : shahiron@uthm.edu.my
} 


\section{MATEC Web of Conferences}

[9-10] and composite material. However, the principle of AE signal data acquisition system has several limitations. Due to this matter, the objective of this paper is to explore the scaling of the AE amplitude distribution waves generated during the cracking process based on the loading system.

\section{B Value Analysis}

This statistical method is widely used in seismology to characterize earthquake populations. This relationship was established and developed by Gutenberg and Richer in 1949.In terms of AE techniques, the Gutenberg-Ritcher formula had been modified as [10-13]:

$$
\log _{10} N=a-b^{\prime} A_{d B}
$$

whereas $A_{d B}=$ peak amplitude of the $\mathrm{AE}$ events in $\mathrm{dB}$.

$$
A_{d B}=10 \log _{10} A_{\max }^{2}=20 \log _{10} A_{\max }
$$

Then, the b-value is calculated as the slope of log linear plot of the AE frequency magnitude distribution as seen in Figure 1.

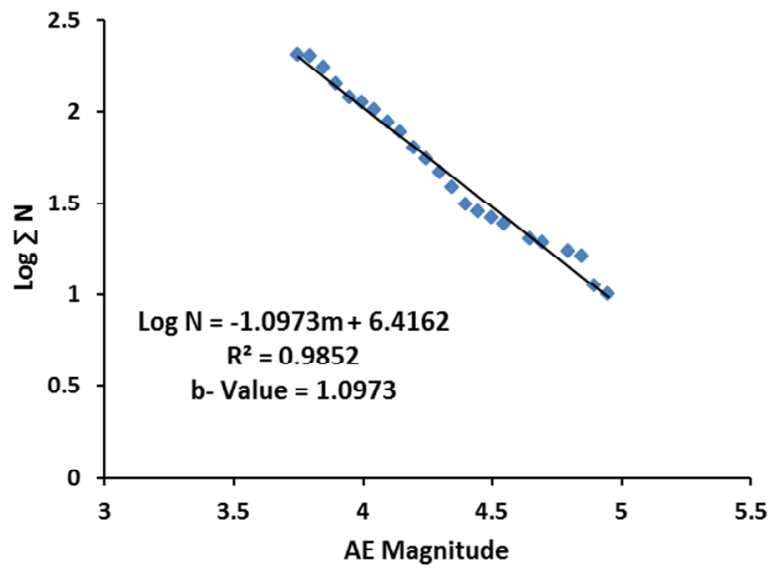

Figure 1. Sample calculation of B-value analysis.

Finally, the values are compared to define and summarize the type of cracking and cracking process (refer to Table 1).

Table 1. Quantitative results analysis [11].

\begin{tabular}{cc}
\hline Value & Description \\
\hline Value $>1.7$ & Micro-cracks are dominant or Macro-cracks are \\
$1.2<$ value $<1.7$ & opening \\
Value $<1.2$ & Uniformly distributed cracking \\
& Macro-crack forming \\
\hline
\end{tabular}

\section{Laboratory Work}

The beam specimens with the following dimensions (150 X 250 X 1900) mm were prepared according to BS8110 for this research as seen in Figure 2. The specimens were tested using a four- 
point bending setup under cyclic load test (CLT). All the beams specimens were reinforced by $2 \mathrm{~T} 12$ and 4T12 longitudinal rebar for compression and tension respectively. The designed concrete strength is $40 \mathrm{MPa}$ with a curing process of 28 days according to the DOE method. The beam specimens were placed on a steel support with a neoprene pad to reduce acoustic noise during the test. The beams tested were loaded under a cyclic load test (CLT) system with a four-point bending tests and were monitored throughout the test using an AE monitoring system as shown in Figure 3.
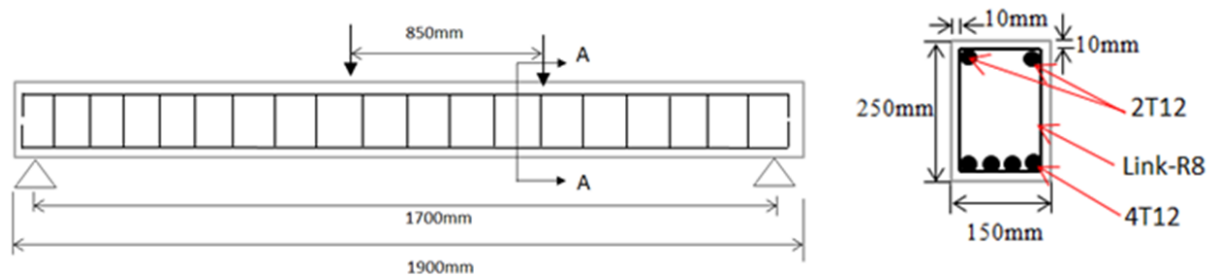

Section A - A

Figure 2. Beam specimens.

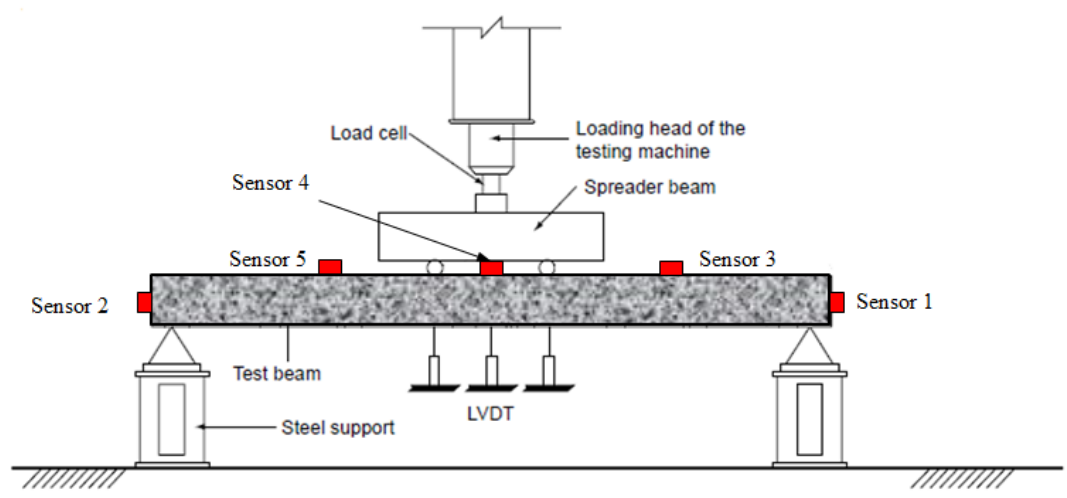

Figure 3. Experimental setup with four point bending test and AE system.

The beam specimens were loaded at a rate of $0.5 \mathrm{~mm} / \mathrm{min}$ using a hydraulic jack system. The Cyclic Load Test system was applied with a starting value $0.5 \mathrm{kN}$ and the first loading cycle was increased up to $20 \%$ of the ultimate load and held for three minutes before releasing $10 \%$ of the calculated ultimate load. This was held for a further three minutes before the next cycle was applied. These procedures were repeated in the second cycle with a similar load level to complete the loading set (LS). This loading and hold procedure was continued with increasing load until ultimate failure.

\section{Result Analysis}

Figure 4 presents amplitude versus time of each load set for the CLT method. The highest amplitude began from service load level (LS4), where the amplitude of hits ranged from 45dB (threshold level) to $96 \mathrm{~dB}$. In addition, the range value of amplitude from $95 \mathrm{~dB}$ to $100 \mathrm{~dB}$ kept increasing when the load set was raised up until failure. Most the high amplitude values indicate a higher value throughout the fracture process. This is clearly seen in LS5 to LS8. The AE amplitude raw data is calculated for $b$ value analysis to determine the type of cracks and fracture process. A detailed equation is shown in Equation (2). 


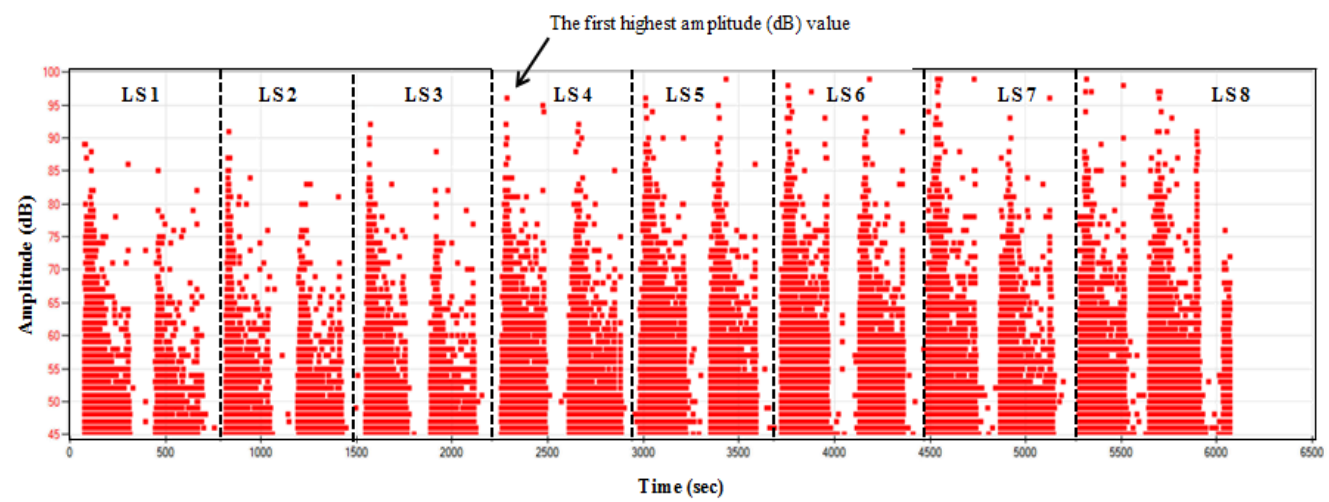

Figure 4. AE amplitude.

The trends of the b-value analysis were then plotted after using statistical analysis (seen in Figure 5 ). The pattern of the development of fracture process could be clearly observed in terms of microcracks and macro-cracks in concrete structure for each load set. From Figure 5, three phases of the fracture process were identified namely the initial load phase, service load phase and failure phase.

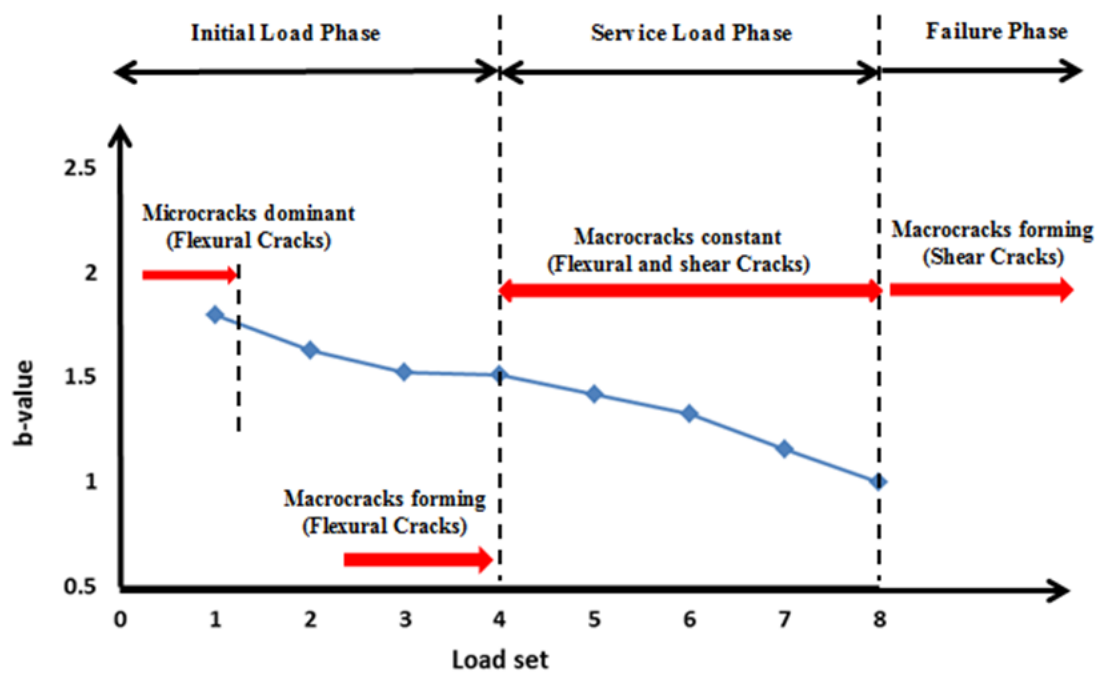

Figure 5. B-value analysis.

From Figure 5, micro-cracks were considered as first cracking and were dominant during the early stage of deformation at LS1. Therefore by increasing the loading to LS3, the macro-cracks began to form and grow as well due to the deformation process and movement from initial load phase and service load phase. At this time, the cracks were classified as flexural cracks and the cracks developed mostly at the bottom of the mid span between two supports.

At the second phase of service load, the macro-cracks were constant and uniformly distributed along the beam which can be recognized during this phase. Based on the visual observation, no new cracks appeared on the beam structure. The flexural cracks continued to grow with some diagonal shear. Subsequently, the macro-cracks were formed and opened up as the beam was failing. At this failure phase, the flexural cracks did not grow to the top, but the diagonal shears at the beam support spread upwards toward the loading point. This analysis was supported by real observation as presented in Figure 6. 


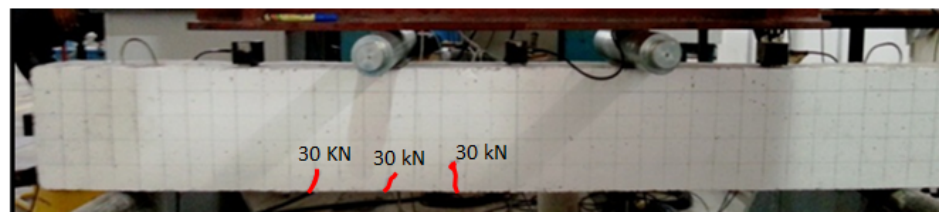

(a)

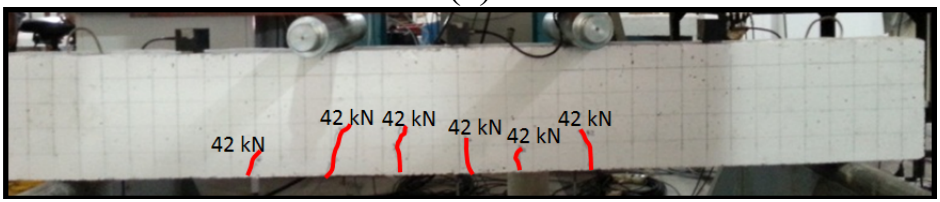

(b)

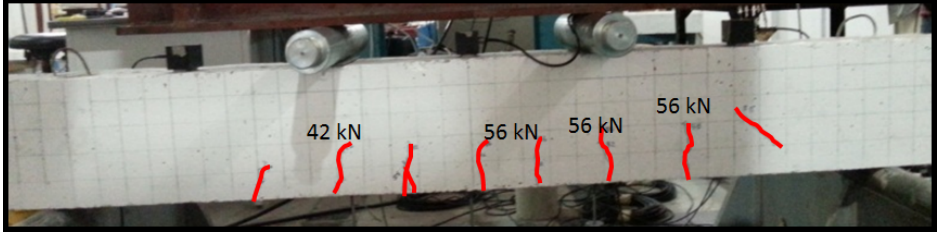

(c)

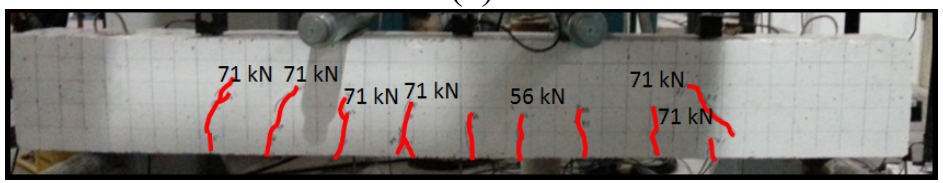

(d)

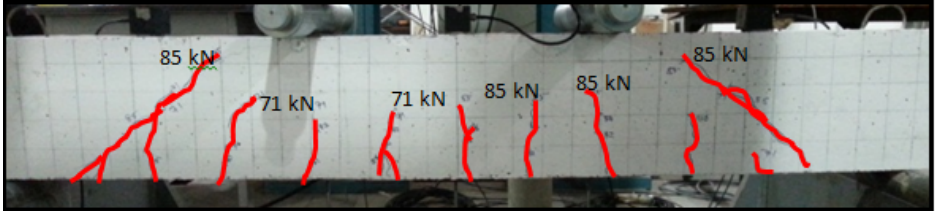

(e)

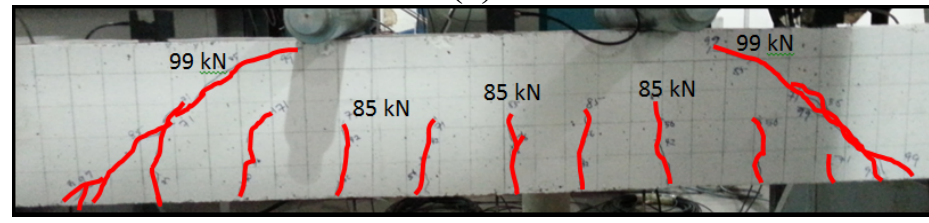

(f)

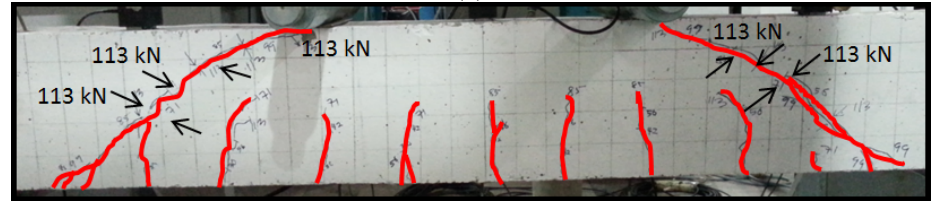

(g)

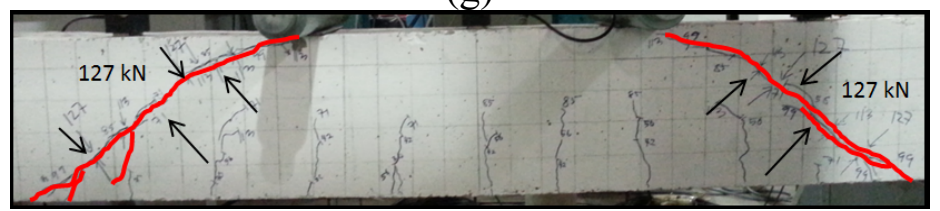

(h)

Figure 6. Real observation. 
Figure 6 (a) - (h) presented the typical development of cracking and fracture process from LS1 to LS8. During the initial stage, micro-cracks appeared on the middle part of the beam from a load set of $32 \mathrm{kN}$ to $43 \mathrm{kN}$ as shown in Figure 6 (a) - (b). This type of crack is known as flexural cracking. At this time, the tension steel began to bear the load and contributed to the overall stiffness.

Nonetheless, the loading increased from approximately $60 \mathrm{kN}$ to $71 \mathrm{kN}$ which is above service load level. The flexural cracks continue to grow and simultaneously some diagonal cracks were formed between support and loading point as shown in Figure 6 (c) and (d). Throughout this point, the stirrup carried shear load and contributed to the global stiffness of the beam. This type of crack is classified as mixed mode cracking (flexural and shear). When the loading increased to the next LS5, the flexural cracks grew quickly between two points loading to form major cracks and spread to the compression zone. In addition, the shear cracks started to form near both supports when the loading was increased to approximately $85 \mathrm{kN}$ as shown in Figure 6 (e). From loading of approximately $100 \mathrm{kN}-120 \mathrm{kN}$, both diagonal shears are spread upwards to the loading point, while the flexure cracks show no notable change as presented in Figure 6(f) and (g).

This period is known as diagonal crack development. Eventually, the flexural and shear cracks become widely open and are connected together when the loading reaches the final point, Figure 6 (h).

\section{Conclusion}

From the analysis, it was found that the trend of AE amplitudes in b-value method managed to develop the process of micro-cracking and macro-cracking for RC beams subjected to the CLT method. In addition, the correlation between the fracture processes in concrete and the localization of damage was established

\section{Acknowledgement}

This work was supported by Universiti Tun Hussein Onn Malaysia's Short Term Grant (U114) and Universiti Sains Malaysia

\section{References}

[1] N. Md Nor, A. Ibrahim, N. Muhamad Bunnori, H. M. Saman, S. N. Mat Saliah and S. Shahidan, Diagnostic of fatigue damage severity on reinforced concrete beam using acoustic emission technique, Journal Engineering Failure Analysis, 41, 1-9, (2013).

[2] S. Shahidan, R. Pulin, N. Muhamad Bunnori and K. M. Holford, Damage classification in reinforced concrete beam by acoustic emission signal analysis, Construction and Building Material, 45, 78-86, (2013).

[3] S. Shahidan, N.M. Nor and N.M. Bunnori, Overview of moment tensor analysis of acoustic emission signal in evaluation concrete structure, IEEE 7th International Colloquium Signal Process, 15-18, (2011).

[4] D.G. Aggelis, A.C. Mpalaskas and T.E. Matikas, Acoustic Emission and Related Non-Destructive Evaluation Techniques in the Fracture Mechanics of Concrete, Elsevier, (2015).

[5] K.M Holford, R. Pullin, S.L. Evans, M. J. Eaton, J. Hensman and K. Worden, Acoustic emission for monitoring aircraft structures, Proceedings of the Institution of Mechanical Engineers, Part G: Journal of Aerospace Engineering, 223(5), 525-532, (2009).

[6] C. Grosse, M. Ohtsu and T. Shiotani, Acoustic Emission Testing, Springer, Berlin, (2008).

[7] G.K Kocur and T. Vogel, Classification of the damage condition of preloaded reinforced concrete slabs using parameter-based acoustic emission analysis, Construction and Building Materials, 24(12), 2332-2338, (2010).

[8] W.C. Choi and H.D. Yun, Acoustic emission activity of CFRP-strengthened reinforced concrete beams after freeze-thaw cycling, Cold Regions Science and Technology, 110, 47-58, (2015). 
[9] S. Gresta and G. Patane, Variation of b value before the etnean eruption of March 1981, Pure and Applied Geophysics, 121(2), 287-295, (1983).

[10]I.S. Colombo, I.G. Main and M.C. Forde, Assessing damage of reinforced concrete beam using " $b$-Value" analysis of acoustic emission, Journal of Material in Civil Engineering, 15(3), 8991561, (2003).

[11]R.V. Sagar, B.K.R. Prasad and S.S. Kumar, An experimental study on cracking evolution in concrete and cement mortar by the b-value analysis of acoustic emission technique, Cement and Concrete Research, 42(8), 1094-1104, (2012).

[12] S.G. Shah and J.M. Chandra Kishen, Use of acoustic emissions in flexural fatigue crack growth studies on concrete, Engineering Fracture Mechanics, 87, (2012).

[13] S. Shahidan, N.M. Bunnori, N. Md Nor and S.R. Basri, Damage severity evaluation on reinforced concrete beam by means of acoustic emission signal and intensity analysis, IEEE Symposium on Industrial Electronics and Applications, 337-341, (2011). 